Article

\title{
On Resilience
}

\section{David Stark}

Department of Sociology, Columbia University, 606 W. 122nd Street, New York, NY 10027, USA; E-Mail: dcs36@columbia.edu; Tel.: +1-212-854-3972

Received: 13 September 2013; in revised form: 3 January 2014 / Accepted: 16 January 2014 / Published: 10 February 2014

\begin{abstract}
This commentary reviews key themes posed by papers in this Special Issue and points to open questions. For example, does resilience in socio-technical systems degrade with use or, like immune systems, is resilience upgraded with use? Similarly, is resilience about responding in the face of the rare event? Or, is it being prepared for the rare event? Is it useful to think about the evolution of resilience? What are the risks posed by models of risk? That is, do models to reduce vulnerability to risk, increase vulnerability? What is the role of reflexivity in the analysis of resilience?
\end{abstract}

Keywords: resilience; models of risk; risk of models; observation theory; reflexive modeling

\section{Introduction-From Human Beings to Being Human}

It is as a sociologist that I write the reflections that conclude this interdisciplinary volume. For some, this might seem to be the moment when people, real honest to goodness people, are brought back into the story. In that view, we can talk all we want about resilient systems or geographies of resilience, but, when it finally comes down to it, what really matters are people. In the end, it is that unreducible human factor that is most important for resilience. Sociology, as the study of human beings, is the discipline that will place people front and center.

I am afraid that I must disappoint such a reader. For, although my accounts of particular instances of resilience are populated by actual people [1-4], I do not regard sociology as the study of human beings. Instead, I see my discipline's task as the study of being human. The change of word order is small, but the difference is consequential. If we study only human beings, we might be able to get away with examining the interactions of these flesh and blood creatures (along, of course, with their thoughts and minds, their aspirations and fears). But as soon as we turn to the problem of being human, we become aware that we cannot focus on people alone, even if we attempt to take into account all the 
interactions that we conventionally think about as "social." We are that species which has evolved (indeed, more accurate to say co-evolved) with our non-humans-cultural objects, material artefacts, technologies, models, scientific theories, and so on. To be human is be involved in complex relationships not only with other people, but also with the humanly shaped environment that is, in one sense, apart from us, and yet in another sense, is a part of our humanity. My starting point, then, is that we can gain a better understanding of resilience when we see it through the lens of socio-technical relations between humans and their non-humans.

\section{Resilience-Degrading or Upgrading with Use?}

The first question that I will pose for further research can be introduced by two exemplary cases of resilience, neither of which is a socio-technical system. The first is a pair of reasonably high quality athletic sneakers. The second case is an immune system. Both are examples of resilience. The resilience of the sneakers is quite literally that they bounce back. But in addition to this dimension we can think of another, along which our two examples are very different. The sneakers, as my shoe salesman and the trainer at my gym remind me, loose resilience with use. By contrast, immune systems need some shock to build resistance and hence resilience. Are social systems more like sneakers or more like immunity? Restated, under what conditions do resilient socio-technical systems degrade with use? And in what ways do socio-technical systems become more resilient only when the system is shocked and stressed?

This points to larger questions about learned resilience in socio-technical systems. Are they like immune systems in which small exposures to stress can trigger mechanisms of resistance and resilience? Alternatively, is the notion of inoculation or acquired immunity not relevant in the case of disasters because they are of an entirely different magnitude than "normal" shocks? As the chief technology officer of a World Trade Center firm that lost its office and many of its employees in the September 11th attack told me: "You've heard the expression 'Every happy family is happy in the same way, but every unhappy family is uniquely miserable?' Well, every normal day is normal in a similar way. But every disaster is completely unique. It's for that reason that, yes, you need to be prepared but there are things going to happen that you could never expect” [1].

\section{Resilience-Responding to or Preparing for Rare Events?}

If the first unanswered research question is whether resilience degrades or upgrades with use, the second is whether resilience is about responding to or being prepared for rare events. What is the role of rare events in understanding resilient socio-technical systems? Is resilience about responding in the face of the rare event? Or, still far from exhaustive of the pertinent questions, is it being prepared for the rare event? Within that problematic, can small events make for such preparation? And could the stimulating events themselves be small? If so, do we need lots of such small events to be prepared for the rare big event? Alternatively, and staying here within the immune system metaphor, perhaps we would be mistaken to think of an immune system from the standpoint of an inoculation (a small rare event prepares for a later big event) but one in which what matters is how the system responds to all kinds of events whether rare or not rare. And, moreover, that the system is robust when it can learn from events that are not only rare but are also surprises that are outside the set for which there are 
already existing solutions. ${ }^{1}$ (A low probability event could be rare, but also because it is already in the category of a known possible event could be thought of as expected even with low probability.) With this in mind we need to emphasize the difference between planning and preparation. Planning requires that parameters are known. One cannot plan for the radically unexpected; but it is possible to be prepared. In this sense, a resilient system does not eliminate vulnerability. In fact, the continued exposure to vulnerability is one of the key features of the system. Among the resources of such a learning system is vulnerability itself.

\section{Resilience, Robustness, and Change}

Sometime before 2000, while participating in an ongoing seminar at the Santa Fe Institute, several of us were asked to provide examples of robustness. My contribution: the Volkswagen Beetle. With the Concept 1 car design by J Mays and Freeman Thomas, the New Beetle demonstrated robustnessthe ability to maintain identity amidst transformation. The Vespa scooter could be another, very similar, example [5].

Robustness is paradoxical. In place of the familiar maxim, "Plus ça change, plus c'est la même chose" (the more things change, the more they stay the same) we find something quite different: sometimes things have to change to stay the same.

One of the interesting and challenging aspects of resilience in socio-technical systems (as well as social systems more conventionally defined) is the problem of the pertinent identity and the relevant time frame. Take, for example, the epochal economic, political, and social upheavals that took place after 1989 in Eastern Europe and (only a few years later) the former Soviet Union. Say, for example, that we looked at the East European cases a decade after the events of 1989. Some of the countries might appear more resilient in the face of the "shock" to the system, whether that be conceptualized as "market shock" or the shock of system transformation more generally. We could think of greater winners and losers, defining this in terms of ability to "bounce back" especially if we use levels of GDP growth as a metric for resilience. Alternatively, we might think about resilience as an ability to learn from the shock. In that case, we might measure resilience in terms of innovation or some other ongoing property of a more flexible and responsive polity, whether or not such metric correlated with levels of growth of GDP [6-8]. Yet again, from a longer historical time frame, one could think of the "shock" not as the perturbation of the 1989 system transformation but as the shock of forty years of Soviet imposed state socialism. Resilience would then be measured by the extent to which the respective societies "returned to normalcy" along some prior East European trajectory. Note that none of these concepts is unproblematic.

1 Prior to the September 11, 2001, security analysts might have (and in all likelihood had) calculated the odds of a terrorist attack on United States territory. But it is highly unlikely that an analyst had prepared estimates of the likelihood that four passenger jets would be seized and turned into weapons, targeting nearly simultaneously four strategy and highly symbolic assets. Such a rare event existed as a category of rare events only in the minds of those who organized and carried out the attack. 


\section{The Evolution of Resilience?}

We turn now more explicitly to socio-technical systems as human-non-human hybrids. Doing so in the context of longer historical time frames suggests that we might think about the evolution of resilience. Over many generations, human beings have developed socio-technical practices to protect them from vulnerabilities and to respond to shocks. From that long time perspective we see an increasing socialization of risk and vulnerability. Increasing socialization means that people took into consideration those around them, starting with small groups, families, and tribes. To those they loved they extended cooperation. There will be times when I am vulnerable and times when you are vulnerable, and so we work together to develop various kinds of communitarian structures and practices to deal with these vulnerabilities.

New institutions emerge with the rise of agriculture and then of manufacturing. Members of a trade, for example, create associations. We carpenters, for example, create a funereal association so that, when your father dies, you can draw on the fund for his funeral. With the nation state come still higher levels of socialization of risk-insurance, pension plans and health care schemes. And in our current epoch we see the rise of humanitarian aid-international communitarianism—at the global level.

One way of thinking about the socialization of resilience is via the notion that some larger unit will care for the vulnerabilities of constituent parts (families for individuals, clans for families, tribes for clans, federal governments for member states, the international community for countries wracked by calamity). The counterpart view is that the mechanisms for maintaining security become forms of threat. For example, as sedentary societies produce agricultural surpluses, they have crops and warehouses to protect, surpluses to pay for units specialized in warfare, military entanglements resulting from these, and new threats to security as a consequence. Similarly, measures to guard against the elements, by providing shelter, warmth, and clothing, as well as to provide for food by irigating and fertilizing crops, can be destabilizing, ultimately threatening delicate climatic balances. Resilience, in this view, would evolve-and the processes driving the evolution of resilience would include the very mechanisms that were intended to provide for resilience.

Several of the papers presented at the conference address these themes. For example, the paper by Gabriela Christmann and Oliver Ibert [9], although not cast in a long historical time frame, explicitly refers to processes in which resilience strategies can be seen to be evolving. Katrina Brown in her presentation does take the longer view but with a very different approach, arguing against the notion of vulnerability and resilience going all the way back to tribal societies. Instead, she historicizes the concepts. Yes, there have always been vulnerabilities, but the self-conception of people and of society as vulnerable and resilient were concepts that emerged historically_and not that long ago.

Ash Amin writes about the end of a long historical development in which elites and masses had made compromises that brought about the welfare state. With the simultaneous rise of markets and of nation states came the emergence of national elites competing with elites in other nations. And so also emerged the dominated classes who demanded the exercise of rights and threatened disruption if these were not recognized. In the resulting compacts that were made between a national elite and its respective subordinate classes, vulnerabilities were socialized in the form of the welfare state. Amin sees our epoch as one in which these structures and practices are being set aside. Moreover, cities are 
the key sites where the dominant and the dominated, instead of recognizing and institutionalizing their interdependence, are becoming increasingly separated.

We can think of this process as the new medievalism, in which elites in their contemporary castles have much more in common with elites in other castles than with the citizens with whom they inhabit the same city. They are a world onto themselves; they often enjoy the protection of private security forces; and they travel freely to the other top 100 cities where, surrounded by the same mauve colored wallpaper in any of the international hotels, they feel comfortably at home. Most importantly, they have, or they think they have, no need for any kind of solidarity with the dominated who live in their communities.

Guruduth Banavar, Vice President and CTO Global Public Sector at IBM New York also puts his attention on cities, observing in his presentation at the Berlin conference that "Cities are a world unto themselves. The top 100 cities have their own network." For Banavar, the evolutionary course of resilience runs "from empire to nation state to city". In his emphatically evolutionary view, the new information technologies are like a radical new species at the end of a long process of evolutionary development. In his vision, these new technologies promise the possibility of the automation of resilience. Susan Christopherson, by sharp contrast, argues that these new big data systems actually threaten resilience because they undermine the highly localized and self-managed practices that have long been the basis for first response in situations of crisis and calamity. The lesson suggested here is that our research should be alert to the ways in which attempts to mitigate risk and protect against disaster can compound risk and provoke new vulnerabilities. If resilience evolves, it does so unevenly at best and with the possibility, at worst, of a trend toward ever widening threat brought about by measures originally designed to protect.

\section{From Security to Securities: The Risks of Models of Risk}

Among the first systematic studies of resilience in a social system, I think of the research carried out after the Second World War about the effects of allied bombing on the German economy. The first of these was the United States Strategic Bombing Survey, commissioned by Franklin Roosevelt while war was still being waged in November 1944 and released at the war's end in September 1945. The board of experts was directed by Paul Nitze who became one of the chief architects of U.S. policy toward the Soviet Union. It included the Keynesian economist John Kenneth Galbraith who had served during the war as deputy director of the Office of Price Adminstration; diplomat George Ball who would later become well known for his opposition to escalation of the Vietnam War; and the organizational psychologist Rensis Likert who had just developed the first national geographic sampling frame and would go on to set up the Survey Research Center at the University of Michigan and develop the 5-point psychometric "Likert scale".

While Galbraith pointed to the commission's findings indicating that allied bombing was ineffective, Nitze sided with Pentagon officials who maintained that strategic bombing had been decisive in bringing about the war's conclusion. What matters for our purposes is not the official report itself but the fact that the study involved systematic research about resilience. Just a few years later, the methodologies developed in the course of the study would find a new object of investigation in research on the anticipated effects of nuclear war on the United States, leading to increasingly 
sophisticated input-output tables of the national economy, new models for economic simulations, and the further development of operations research [10-12]. These new models of the economy moved from thinking about aggregates to thinking about interconnected flows and from event modeling to logistics modeling that recognized the spatial and temporal interdependencies between different production facilities and thus examined the post-attack capabilities of these facilities through the lens of “critical networks” ([13], p. 30). Vulnerability and hence resilience were thus reconceptualized.

These models, in turn, figured in the strategic management of President Nixon's Wage and Price Control policy announced in August 1971 and triggered by 6.1\% unemployment. ${ }^{2}$ This policy once again brought economists to work alongside engineers from operations research. Their continued efforts resulted in the change from actuarial to probabilistic models of risk; in the shift from modeling the national economy to models of financial markets; to notions of stress tests applied not to physical objects but to financial instruments; to the use of models to reduce vulnerability to risk by traders, by hedge funds, and by banks; and eventually to the use of models as a regulatory device. Thus, from the first systematic studies of resilience we find an unbroken link of conceptual and methodological developments, moving from the field of security to the field of securities and leading to contemporary models of risk-models, moreover, which take into account that other actors are also using models in attempts to design resilience in response to risky futures.

Recent work in the social studies of finance suggests that models of risk can be risky. Donald MacKenzie [14], for example, shows how models designed to calculate the risk of securitized mortgages contributed to the recent financial crisis. In several recent papers, Elena Esposito [15,16] applies observation theory to the field of finance with similar conclusions. In her paper on "The Structure of Uncertainty," Esposito proposes the idea that "the real purpose and function of the market is to provide an arena for the mutual observation of observers” ([16], p. 10). For her, the most interesting aspect of the circularity of observations (observers observing observers) pertains to uncertainty about the future [17]. And the most troubling aspect is that models that predict the future can and will, by being used, bring about a different world than the one predicted. This is a diabolical circularity: The more a prediction is followed, the more it will modify the conditions on which it was based, and thereby change the world. Or, as the Yankee philosopher Yogi Bera so aptly stated: "The future ain't what it used to be.” Observations about the future bring about different futures $[15,18]$.

Esposito notes that any model needs to make assumptions about the actions of others. Things get really interesting, she argues, when models become more sophisticated and begin to take into account that others are not simply acting but are acting on the basis of models (which themselves take into account that others are using models, each of which is probability based). As models become more sophisticated, more powerful, and better able to take into account model risk, prices become more volatile and the system as a whole less predictable. That is, the reliability of models contributes to the unpredictability of the system: "Under these conditions, every reliable forecast is destined to falsify itself, because the future reacts to the expectations imposed on it-where every additional reliable forecast contributes to an increased unpredictability of the future” ([15], p. 370).

2 In effect, the same new models of the economy that gave the Office of Emergency Preparedness tools to understand the effects of nuclear strikes could also be used to understand the effects of potential industrial or general strikes by trade unions [12]. 
My research with Daniel Beunza also finds that measures that perform well in error detection and in limiting exposure to calamity at the individual level can lead to the amplification of error and disaster for the collectivity. In a recent paper, "From Dissonance to Resonance: Cognitive Interdependence in Quantitative Finance" [19], we ask the question: How do traders deal with the fallibility of their models? In particular, how do they deal with the fact that, in identifying patterns in the markets, these same instruments can also blind the trader from seeing some things? As instruments of perception and indeed, like the optic nerve itself which allows us to see but must also produce a blind spot—models that reveal also conceal.

How does the trader avoid such cognitive lock in? The answer is that traders leverage the fact that other traders are observing from a different vantage point. The traders at the merger arbitrage desk we studied could not observe what is on their rivals' screens. That is, as a trader I cannot observe your observations directly, and I don't have access to your model. What I would like to do is make reasonable inferences about your model. Beunza and I show that, in the case of merger arbitrage, traders place on their screen an image of the "spread plot" which they skillfully use as a representation of the aggregate views of their rivals.

When the spread plot moves in a direction different from one's own estimates, traders can ask, "What am I missing?” and make corrections in their models. In itself, watching the spread plot is a first order observation. But when the spread moves in a different direction than the estimates derived from my proprietary model, the resulting triangulation is a second order observation that allows me to make inferences about how you are interpreting the world which can cause me to reflect on (to think again about) my own model. Such "reflexive modeling" can help an individual trader to avoid disaster. But it should come with a warning label: when the system lacks requisite diversity, the cognitive interdependence can create positive feedback that yields an arbitrage disaster-such as the $\$ 2.8$ billion in losses to merger arbitrageurs (including the team we studied) in the GE-Honeywell deal. When the system lacks diversity of viewpoints, the same practices that do prove effective in mitigating individual cognitive lock in can lead to a collective lock in of enormous proportions.

\section{Information Architecture Is Politics in Code}

In his paper here, Gernot Grabher asks how we can learn from rare events. And he poses that question both for the analytic observer and for the participants themselves. In addition to learning from events that almost never occur, we could go on to ask how to learn when events are very small. This is the problem that Bruce Goldstein posed in his presentation [20]. We can go on and ask how can we learn without disasters? Most importantly, what counts as a disaster? Ash Amin points us in that direction. The small events-a child dies of malnutrition, a young person dies of violence, a mother dies of an untreated disease. Large in a life to be sure; but small on some world historical scale. Yet, what if there are tens or hundreds of thousands of such small events every day? The numbers are at large scale, but still the events are small. Must it be socially and politically recognized as a disaster for us to learn from it?

Amin is not sanguine about such prospects. What optimism he expresses is based on what he sees in structures and processes of the most mundane and localized types. These are hybrid systems in exactly the sense with which I opened this essay and associations of human and non-human. Amin refers to 
them as the city's “technological unconscious” but he does not have in mind the eyes of all-seeing surveillance and information technologies. No, he finds reason for hope in the most basic-water and sewer systems. For it is in the struggle for such absolutely basic urban amenities that the dispossessed can counter impoverishment, both because of the direct, immediate actual benefits it can provide but also because it can indirectly be the social organizational basis for political resistance in the longer term. Meanwhile, the arrangements around such material provisioning provide a social infrastructure that could form the basis for resilient response should other kinds of disasters strike.

Although he does not use the term, Guruduth Banavar also thinks of a kind of urban technological unconscious. But unlike that of Ash Amin, his is emphatically one that is information based. As he told us at the Berlin conference, "Pretty much everything in the physical world has a representation in the information world.” But, as I responded to him at the conference, recent research suggests that the IBM labs must think through some further steps. First, following MacKenzie [14] and Esposito [16] as well, the algorithms of automated resilience are not simple representations of the world. They are engines that reshape the world at the same time that they code it. Second, the more that the instruments for automated resilience begin to model human behavior, the more (to be realistic) they will need to bring into their models the fact that agents are also using models. The paradox, as we saw in the work of Esposito mentioned above, is that this greater realism produces models of such instability that it increases rather than decreases uncertainty.

As I also posed to Guruduth Banavar in Berlin, there is the question of politics around automated resilience. Banavar speaks as if these systems are only technical. But, to insist on both sides of such complex hybrids, they are, in fact, socio-technical. As such, they are shaped by politics - not merely the partisan politics that so inflicts our systems of governance but the deeper politics shaped and in turn shaping inequalities. Someone once said that architecture is politics in stone. In our era, information architecture is politics in code. This can remain a denunciation, even one of resignation. Or, instead, it can mean that policy makers, citizen associations, and yes software programmers take up the challenge to put a different, more inclusive, more participatory, and more democratic politics into code.

\section{From Redundancy to Reflexivity}

Gernot Grabher's account of the preparation for the 2012 London Olympic Games highlights, first, the importance of goal ambiguity. For the particular case, what mattered was the simultaneous planning of the event and of the infrastructural legacy that would remain after the Olympics. Grabher emphasizes, secondly, the importance of evaluative ambiguity. It was the existence of multiple, indeed rival, performance principles that generated better search processes in the planning and preparation phases. Thirdly, Grabher stresses the difference between adaptation and adaptability. A system that is perfectly adapted to its environment would be most efficient-according to principles of allocative efficiency. But, as perfectly adapted, it would have no slack to respond if and when the environment changes. The more adapted, the less room for maneuver. Adaptability, by contrast, refers to the dynamic reproduction of slack, i.e., to the presence of some resources which were not deficient when measured from the perspective of allocative efficiency (see also [21,22]). 
Of these, for the challenge of resilience as for the challenge of innovation, most important in my view is diversity of evaluative principles. I stress diversity, a word that, surprisingly for me, was not often voiced at the Berlin conference. In my view, diversity of evaluative principles (call them principles of worth) is important because it can be a basis for organizational reflexivity. If there are heterogeneous criteria of worth, it is less likely that we will lock in to one "best" way of doing things. In so doing, we will not merely preserve slack—redundancy of the same type of resource-but will preserve diverse practices. This means, in the first place, that we have a greater diversity of practices available for recombination when the environment changes. And because we have not organizationally locked in to only one way of doing things, we are also not cognitively locked in. This greater reflexivity means that we are more likely to be able to recognize that, in changed circumstances, there are aspects of the situation that can be configured as resources. In that case, resilience is not just having extra resources held as redundant slack (at the outset, quantitatively more but not qualitatively different) nor is it suddenly being granted more resources externally. Instead it is an internal ability to acknowledge and utilize what was there but had not been already recognized as a resource [22].

Vulnerability is not inherently negative. To be vulnerable is itself something valuable and inevitable. It defines us as humans. To be resilient is not to have eliminated vulnerability. In fact, one of the dangers of security measures is that, in trying to conquer vulnerability, they can damage processes which are at the basis of resilience.

\section{Acknowledgements}

I am grateful to Jorg Sydow and especially to Elena Esposito for comments and suggestions while I was revising this essay.

\section{Conflicts of Interest}

The author declares no conflict of interest.

\section{References}

1. John Kelly, and David Stark. "Crisis, Recovery, Innovation: Responsive Organization after September 11 ${ }^{\text {th }}$.” Environment and Planning A 34, no. 9 (2002): 1523-33.

2. Daniel Beunza, and David Stark. "The Organization of Responsiveness: Innovation and Recovery in the Trading Rooms of Lower Manhattan.” Socio-Economic Review 1, no. 2 (2003): 135-64.

3. Daniel Beunza, and David Stark. "Resolving Identities: Successive Crises in a Trading Room after 9/11.” In Wounded City: The Social Impact of 9/11. Edited by Nancy Foner. New York: Russell Sage Foundation Press, 2005, pp. 293-320.

4. Monique Girard, and David Stark. "Socio-technologies of Assembly: Sense-making and Demonstration in Rebuilding Lower Manhattan.” In Governance and Information: The Rewiring of Governing and Deliberation in the 21st Century. Edited by David Lazer and Viktor MayerSchoenberger. New York and Oxford: Oxford University Press, 2007, pp. 145-76. 
5. Davide Ravasi, Violina Rindova, and Ileana Stigliani. "Valuing Products as Cultural Systems: A Conceptual Framework and Empirical Illustration.” In The Worth of Goods: Valuation and Pricing in the Economy. Edited by Jens Beckert and Patrik Aspers. Oxford and New York: Oxford University Press, 2011, pp. 297-318.

6. David Stark, and Laszlo Bruszt. Postsocialist Pathways: Transforming Politics and Property in East Central Europe. New York and Cambridge: Cambridge University Press, 1998.

7. David Stark, and Laszlo Bruszt. "One Way or Multiple Paths? For a Comparative Sociology of East European Capitalism.” American Journal of Sociology 106, no. 4 (2001): 1129-37.

8. Laszlo Bruszt, and David Stark. "Who Counts? Supranational Norms and Societal Needs.” East European Politics and Societies 17, no. 1 (2003): 74-82.

9. Gabriela C. Christmann, and Oliver Ibert. "Vulnerability and Resilience in a Socio-Spatial Perspective. A Social-Scientific Approach.” Raumforschung und Raumordnung 70, no. 4 (2012): 259-72.

10. Stephen J. Collier, and Andrew Lakoff. "Distributed Preparedness: The Spatial Logic of Domestic Security in the United States." Environment and Planning D: Society and Space 26, no. 1 (2008): 7-28.

11. Stephen J. Collier, and Andrew Lakoff. “The Vulnerability of Vital Systems: How 'Critical Infrastructure’ Became a Security Problem.” In Politics of Securing the Homeland: Critical Infrastructure, Risk and Securitization. Edited by Myriam Dunn and Kristian Soby Kristensen. London and New York: Routledge, 2008, pp. 40-62.

12. David F. Krugler. This is Only a Test: How Washington D.C. Prepared for Nuclear War. New York: Palgrave, 2006.

13. Onur Ozgode. "Logistics of Survival: Assemblage of Vulnerability Reduction Expertise." Department of Sociology, Columbia University, 2009, unpublished manuscript.

14. Donald MacKenzie. “The Credit Crisis as a Problem in the Sociology of Knowledge.” American Journal of Sociology 116 (2011): 1778-841.

15. Elena Esposito. “The Certainty of Risk in the Markets of Uncertainty.” In Vinzenz Bronzin's Option Pricing Models: Exposition and Appraisal. Edited by Wolfgang Hafner and Heinz Zimmermann. Berlin and Heidelberg: Springer, 2009, pp. 359-72.

16. Elena Esposito. "The structures of uncertainty: Performativity and unpredictability in economic operations.” Economy \& Society 42 (2012): 102-29.

17. Elena Esposito. The Future of Futures: The Time of Money in Financing and Society. Cheltenham: Elgar, 2011.

18. David Stark. "Observing Finance as a Network of Observations: Comment on Esposito." Sociologica 2 (2013): 1-12.

19. Daniel Beunza, and David Stark. "From dissonance to resonance: Cognitive interdependence in quantitative finance.” Economy and Society 41 (2012): 383-417.

20. Bruce Evan Goldstein, Anne Taufen Wessells, Raul Lejano, and William Butler. "Narrating Resilience: Transforming Urban Systems Through Collaborative Storytelling.” Urban Studies, 2013, online first. 
21. Gernot Grabher, and David Stark. "Organizing Diversity: Evolutionary Theory, Network Analysis, and the Postsocialist Transformations.” Regional Studies 31, no. 5 (1997): 533-44.

22. David Stark. The Sense of Dissonance: Accounts of Worth in Economic Life. New Jersey and Oxfordshire: Princeton University Press, 2009.

(C) 2014 by the author; licensee MDPI, Basel, Switzerland. This article is an open access article distributed under the terms and conditions of the Creative Commons Attribution license (http://creativecommons.org/licenses/by/3.0/). 